\title{
化学学科核心素养初高衔接的发展研究 以蛋白质和维生素课堂教学为例
}

\section{甄广慧}

沈阳市第一D—中学

DOI:10.32629/jief.v2i11.2468

[摘 要] 初中学生的化学学科素养, 应引导学生用化学思维解答化学问题, 培养学生通过化学实验, 形成严谨的科学探究精神, 关注课程的 实用性, 培养学生能够将理论知识与实际生活结合起来, 服务生活。另外在化学学科学习中, 教师要注重培养学生团队合作意识, 提高学生 相互协作能力, 在学科教育中培养对学生良好品德的塑造。

[关键词] 化学学科素养; 团队协作; 实验探究

中图分类号: G633.8 文献标识码: A

从文献查阅可知, 学生的核心素养是指学生能够适应终身发展和社 会发展必备品格和关键能力, 化学学科素养主要体现在以下五个方面: 宏观观察与微观探索; 变化观念与平衡思想; 证据推理与模型认知; 科 研与创新; 科学精神与社会责任。学科基础知识是化学学科核心素养的 载体; 学生能力是学生发展化学核心素养的保障; 学科思想方法是化学 核心素养的实质。作为化学教师的学科应具备的包含三个方面的内涵, 学科知识与技术, 学科方法与能力, 学科视野与情怀。初中学生正是世 界观, 人生观, 价值观形成的关键时期, 具备运用新方法解决问题能力, 也能够逐渐以系统和全方位角度来辩证的分析问题。

义务教育阶段的化学课程以提高学生的科学素养为主题, 激发学生 学习化学的兴趣, 培养学生科学探究能力。作为化学教师如何循循善诱, 抛砖引玉, 引导学生形成化学思维解答化学问题, 培养化学学核心素养 是比单纯传授知识更深入的研究契点, 笔者从沪教版九年化学第八章第 3 节《蛋白质 维生素》课堂实例中, 阐述对学生化学学科核心素养的培 养。

\section{1 把握课堂教学知识结构难度, 培养学生自信心}

《蛋白质 维生素》是学生在九年级下学期学习的第 3 种和第 4 种有 机化合物, 是有机化合物认识的入门, 是初高中衔接的有机化学知识。 这一部分内容来源于生活中常见的食物学生在日常生活中经常接触蛋白 质和维生素, 例如鸡蛋, 牛奶, 水果, 谷类含有丰富的这两种营养素。 但对蛋白质具有的性质却很陌生。蛋白质与维生素虽然由碳元素、氢元 素和氧元素组成, 但结构的不同, 决定他们的性质与作用不同, 蛋白质, 维生素知识入门, 既是对之前物质分类与元素种类认识的深入, 又为高 中继续学习有机化合物做好基础, 它存在于初高中衔接知识体系之中。 对蛋白质和维生素了解, 体现了从形象到抽象, 从生活中物质的形象到 结构的抽象。这一部分内容不可给予学生较深较难的知识内容, 因为这 一部分知识与生物、医疗、遗传联系较多, 如何把握此部分的知识难度 与知识容量应当谨慎考虑。

\section{2 小组合作, 培养学生协作处理问题能力}

在学习方法上, 可以同学生查阅相关资料, 生生互动, 相互分享, 这种方式既能培养学生, 搜索, 分析, 篮选, 归纳能力也可促进学生之
间相互合作, 培养沟通表达能力, 在切磋磨合中发现并树立正确的价值 观。

\section{3 探究实验, 培养学生形成科学的探究方法}

蛋白质性质是初中化学教学中较为重要的知识, 更为重要的原因是 它与生活密切相关, 化学知识来源与生活, 更服务与生活, 小到生活常 识。通过将化学课程内容与学生的生活实际相互联系, 即生活情景与社 会实践将初中化学教学与其相互促进, 两者共同构成初中化学生活化教 学。根据本节内容与生活联系, 例如生活中煮鸡蛋, 卤水点豆腐; 甲醛 环境污染, 医疗用的紫外线消毒灯, 化学实验是对课堂的补充与延伸, 既能帮助学生学以致用, 又能培养学生探究能力。鼓励学生掌握如何运 用化学知识爱惜保护我们的生命, 服务我们的生活。学科素养在于培养 一个全面发展的人, 立德树人是我们教育教学任务, 学习致用是我们实 现学习目标的体现。为了让学生充分认识到蛋白质性质的重要性。另外 设计学生分组实验, 使用鸡蛋清作为蛋白质, 分别向鸡蛋清中加入蒸馏 水, 饱和硫酸铵溶液, 硝酸银溶液, 浓硝酸溶液, 观察鸡蛋清发生的明 显变化, 在化学实验中, 激发学生探究乐趣, 形成科学严谨的探究方法, 认真观察实验现象, 积极思考, 努力寻求解决问题的突破点。化学实验 不仅帮助学生掌握学科知识, 更有助于学生日后的科学探究。

化学学科素养培养需要每一名教师在化学课程教学中钻研与思考, 在化学教学中立德树人, 把握课堂教学的内容与方式, 问题具有有效性 与预见性, 坚持用严谨的化学思维引导学生解决化学问题, 培养学生从 化学的视角思考并做出正确的判断, 关注化学与社会结合的热点, 为培 养学生树立社会主人翁的意识而奋斗。

\section{[参考文献]}

[1]贺䎦萍.初中化学教学:生活化不可或缺一九年级化学《水的 净化》教学谈[J].中国校外教育,2019(24):29.

[2]金晓琴.论生活化教学模式在初中化学教学中的应用[J].成才之 路,2017(35):32.

[3]陆芳芳.浅谈初中化学课堂教学的兴趣化、生活化、信息化、探 究化[J].教育实践与研究(B),2017(增刊 1):19-21. 